\title{
Hyperammonemia in uncontrolled Type2 Diabetes Mellitus
}

\author{
Gunanithi.K ${ }^{1}$, Sakthi Dasan.S ${ }^{2}$, Sultan Sheriff.D ${ }^{3}$ \\ ${ }^{1}$ Assistant Professor, Department Of Biochemistry, Melmaruvathuradhiparasakthi Institute Of Medical Sciences \\ And Research,TamilNadu (Affiliated To TN Dr.MGR Medical University,Chennai), India. \\ ${ }^{2}$ Associate Professor, Department Of Biochemistry, Melmaruvathuradhiparasakthi Institute Of Medical \\ Sciences And Research, TamilNadu (Affiliated To TN Dr.MGR Medical University, Chennai), India. \\ ${ }^{3}$ Professor And HOD, Department Of Biochemistry, Melmaruvathuradhiparasakthi Institute Of Medical \\ Sciences And Research, TamilNadu (Affiliated To TN Dr.MGR Medical University, Chennai), India
}

\begin{abstract}
Type 2 Diabetes mellitus, a common metabolic disorder characterized by hyperglycemia and its consequences not only affects the carbohydrate metabolism, also has its effects on lipid and protein metabolism altering the overall metabolic homeostasis in general. The morbidity and mortality that patients with type 2 diabetes mellitus suffers is quite alarming. While most of the complications has its symptoms that alerts the patients to take proper evaluation and its treatment, there are indeed many more of the complications in type 2 diabetes mellitus that comes under the asymptomatic issues but significantly affecting the body slowly but steadily. While everyone as a physician is aware of the hyperglycemia and dyslipidemia associations with type 2 diabetes mellitus, we seldom look for the altered protein metabolism leading to hyperammonemia or so unless the patient is admitted in the ICU setup. Hyperammonemia is quite common among liver disease patients. Though rare, yet significantly there are also other non hepatic causes of hyperammonemia which comes to suspicion only in the childhood disorders. Non hepatic hyperammonemia in adults tends to present with various medical specialities nowadays, which can be bothersomely symptomatic or easily asymptomatic. The key is to have high levels of suspicion in mind and ask for serum ammonia levels. Since serum ammonia levels are in one way or the other linked to the function of the brain, high levels of serum ammonia can affect the morbidity and mortality of patients which is already compromised in patients with type 2 diabetes mellitus. The study was aimed to find whether patients with uncontrolled type 2 diabetes mellitus have disorders of ammonia metabolism. Our study has shown that serum ammonia levels are significantly higher among patients with uncontrolled type 2 diabetes mellitus. Maintaining a high index of suspicion andso its early diagnosis and preventive measures could salvage serious morbidity and mortality.
\end{abstract}

Keywords:Type 2 Diabetes mellitus, Serum ammonia, Hyperammonemia.

\section{Introduction}

Diabetes mellitus type 2, a common disease among adults is characterized by syndrome of hyperglycemia and its consequences. The complications, including both acute and chronic are directly related to the control of blood sugar levels and the impact they have on morbidity and mortality is alarming. Diabetes is fast gaining the status of a potential epidemic in India with more than 62 million diabetic individuals currently diagnosed with the disease ${ }^{[1],[2]}$. In 2000 , India (31.7 million) topped the world with the highest number of people with diabetes mellitus followed by China ( 20.8 million) with the United States (17.7 million) in second and third place respectively. According to Wild et $\mathrm{al}^{[3]}$, the prevalence of diabetes is predicted to double globally from 171 million in 2000 to 366 million in 2030 with a maximum increase in India. It is predicted that by 2030 diabetes mellitus may afflict up to 79.4 million individuals in India ${ }^{[4]}$.Hyperammonemia, a metabolic disturbance whereby serum ammonia levels are high in blood. Ammonia, a product of protein catabolism is usually converted to urea and is excreted in urine by the kidneys. High ammonia levels are toxic to the brain. Usually, hyperammonemia is caused by liver dysfunction commonly liver cirrhosis. But there are also other causes leading to hyperammonemia which includes various forms of urea cycle disorders, which are mainly seen in pediatric population. Non hepatic causes of hyperammonemia are rarer. It includes many inherited and acquired causes and tend to present to a wide range of medical specialities with variable and episodic symptoms ${ }^{[5]}$. Delay in diagnosis can result in development of potentially life threatening neurological complications. This study was conducted with the aim of finding out any disorders of ammonia metabolism among patients with uncontrolled type 2 diabetes mellitus who tends to have altered protein metabolism as a consequence of abnormal glucose homeostasis.

\section{Materials\& Methods}

Fasting Blood sample $(5 \mathrm{ml})$ is obtained from 60 individuals aged $40-60$ years 30 diabetics and 30 controls. Attending medicine / diabetology OPD of our institute MAPIMS,melmaruvathur, India . All 
individuals were interviewed at the baseline by the same investigator for a general medical history and complete medical examination. An informed consent was obtained from all the study participants.

InclusionCriteria:Cases includes patients with uncontrolled type 2 diabetes mellitus ( fasting hyperglycemia ) and Controls includes non diabetic normal healthy volunteers.

ExclusionCriteria :Those individuals with heart failure, cardiovascular disease, liver dysfunction and renal insufficiency were excluded from the study.

\section{Investigations ,performed:}

1. Fasting plasma glucose by glucose oxidase peroxidase enzymatic methodusing fully automated analyser.

2. Serum ammonia by enzymatic method using fully automated analyser.

Statistical analysis was performed using SPSS statistical software.

Comparison of serum ammonia

\section{Results}

\begin{tabular}{|l|l|l|l|}
\hline \multicolumn{5}{|l|}{ Report } \\
\hline Ammonia & Mean & $\mathrm{N}$ & Std. Deviation \\
\hline GROUP & 136.20 & 30 & 70.602 \\
\hline 1( cases ) & 17.77 & 30 & 6.372 \\
\hline 2 ( controls ) & 76.98 & 60 & 77.692 \\
\hline Total & & & \\
\hline
\end{tabular}

\begin{tabular}{|c|c|c|c|c|c|c|c|c|c|c|}
\hline \multicolumn{11}{|c|}{ Independent Samples Test } \\
\hline & & \multicolumn{2}{|c|}{$\begin{array}{l}\text { Levene's Test } \\
\text { for Equality } \\
\text { of Variances }\end{array}$} & \multicolumn{7}{|c|}{ t-test for Equality of Means } \\
\hline & & \multirow[t]{2}{*}{$\mathrm{F}$} & \multirow[t]{2}{*}{$\begin{array}{l}\mathrm{S} \\
\mathrm{i} \\
\mathrm{g}\end{array}$} & \multirow[t]{2}{*}{$\mathrm{t}$} & \multirow[t]{2}{*}{$\mathrm{df}$} & \multirow[t]{2}{*}{$\begin{array}{l}\text { Sig. (2- } \\
\text { tailed) }\end{array}$} & \multirow[t]{2}{*}{$\begin{array}{l}\text { Mean } \\
\text { Differ } \\
\text { ence }\end{array}$} & \multirow{2}{*}{$\begin{array}{l}\text { Std. } \\
\text { Error } \\
\text { Differe } \\
\text { nce }\end{array}$} & $\begin{array}{l}95 \% \\
\text { Interval } \\
\text { Differenc }\end{array}$ & $\begin{array}{l}\text { Confidence } \\
\text { of the }\end{array}$ \\
\hline & & & & & & & & & Lower & Upper \\
\hline \multirow[t]{2}{*}{ ammonia } & $\begin{array}{l}\text { Equal } \\
\text { variance } \\
\mathrm{s} \\
\text { assume } \\
\mathrm{d}\end{array}$ & 55.428 & $\begin{array}{l}0 \\
0 \\
0\end{array}$ & 9.151 & 58 & .000 & $\begin{array}{l}118.4 \\
33\end{array}$ & 12.942 & 92.526 & $\begin{array}{l}144.34 \\
0\end{array}$ \\
\hline & $\begin{array}{l}\text { Equal } \\
\text { variance } \\
\mathrm{s} \text { not } \\
\text { assume } \\
\mathrm{d}\end{array}$ & & & 9.151 & $\begin{array}{l}29.4 \\
72\end{array}$ & .000 & $\begin{array}{l}18.4 \\
33\end{array}$ & 12.942 & 91.982 & $\begin{array}{l}144.88 \\
5\end{array}$ \\
\hline
\end{tabular}

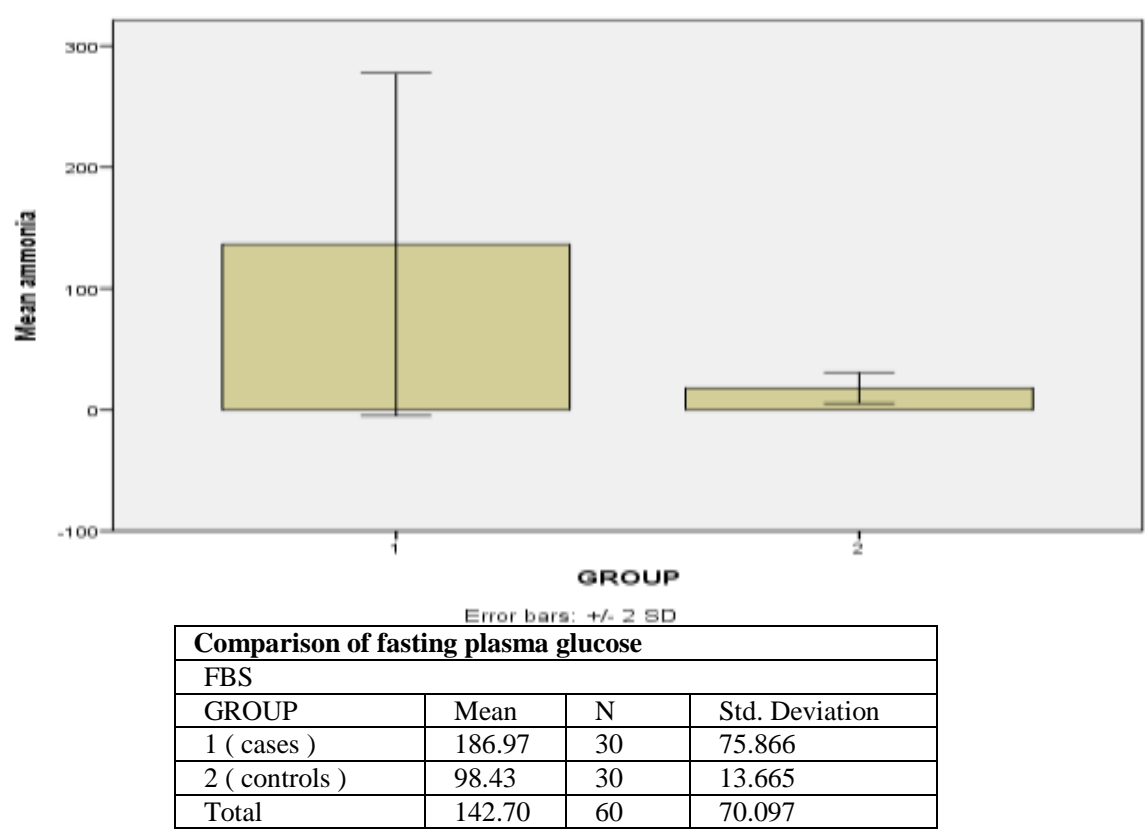


Hyperammonemia in uncontrolled Type 2 Diabetes Mellitus

\begin{tabular}{|c|c|c|c|c|c|c|c|c|c|c|}
\hline \multicolumn{11}{|c|}{ Independent Samples Test } \\
\hline & & \multicolumn{2}{|c|}{$\begin{array}{l}\text { Levene's Test for } \\
\text { Equality of Variances }\end{array}$} & \multicolumn{7}{|c|}{ t-test for Equality of Means } \\
\hline & & \multirow[t]{2}{*}{$\mathrm{F}$} & \multirow[t]{2}{*}{ Sig. } & \multirow[t]{2}{*}{$\mathrm{t}$} & \multirow[t]{2}{*}{ df } & \multirow{2}{*}{$\begin{array}{l}\text { Sig. } \\
(2- \\
\text { taile } \\
\text { d) }\end{array}$} & \multirow[t]{2}{*}{$\begin{array}{l}\text { Mean } \\
\text { Differen } \\
\text { ce }\end{array}$} & \multirow{2}{*}{$\begin{array}{l}\text { Std. } \\
\text { Error } \\
\text { Differen } \\
\text { ce }\end{array}$} & \multicolumn{2}{|c|}{$\begin{array}{l}\text { 95\% Confidence } \\
\text { Interval of the } \\
\text { Difference }\end{array}$} \\
\hline & & & & & & & & & Lower & $\begin{array}{l}\text { Uppe } \\
\text { r }\end{array}$ \\
\hline \multirow[t]{2}{*}{ FBS } & $\begin{array}{l}\text { Equal } \\
\text { variance } \\
\text { s } \\
\text { assumed }\end{array}$ & 11.102 & .002 & 6.291 & 58 & .000 & 88.533 & 14.074 & 60.361 & $\begin{array}{l}116.7 \\
06\end{array}$ \\
\hline & $\begin{array}{l}\text { Equal } \\
\text { variance } \\
\mathrm{s} \quad \text { not } \\
\text { assumed }\end{array}$ & & & 6.291 & $\begin{array}{l}30 . \\
88 \\
0\end{array}$ & .000 & 88.533 & 14.074 & 59.824 & $\begin{array}{l}117.2 \\
42\end{array}$ \\
\hline
\end{tabular}

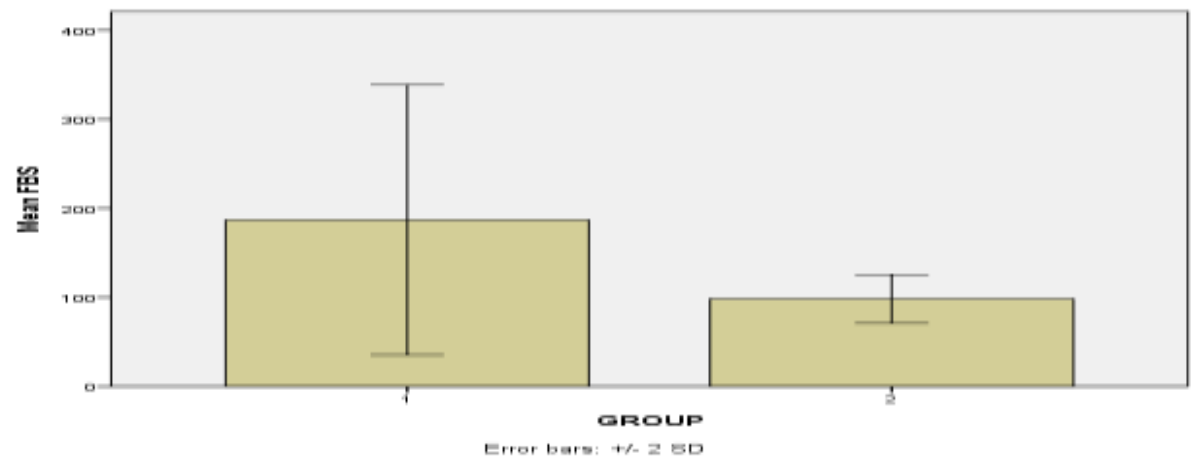

IV. Discussion

Ammonia, the end product of protein metabolism is converted to urea through the urea cycle in liver. Normal blood ammonia levels range from 10-40 $\mu \mathrm{mol} / \mathrm{L}$, compared with a BUN level of 6-20 mg/dL. The total soluble ammonia level in a healthy adult with $5 \mathrm{~L}$ of circulating blood is only $150 \mathrm{mcg}$, in contrast to approximately $1000 \mathrm{mg}$ of urea nitrogen present. An individual is unlikely to become hyperammonemic unless the conversion system is impaired in some way. The normal process of removing the amino group present on all amino acids produces ammonia. The $\alpha$-amino group is a catabolic key that protects amino acids from oxidative breakdown. Removing the $\alpha$-amino group is essential for producing energy from any amino acid. Under normal circumstances, both the liver and the brain generate ammonia in this removal process, substantially contributing to total body ammonia production. The urea cycle is completed in the liver, where urea is generated from free ammonia. The hepatic urea cycle is the major route for disposal of waste nitrogen chiefly generated from protein and amino acid metabolism.

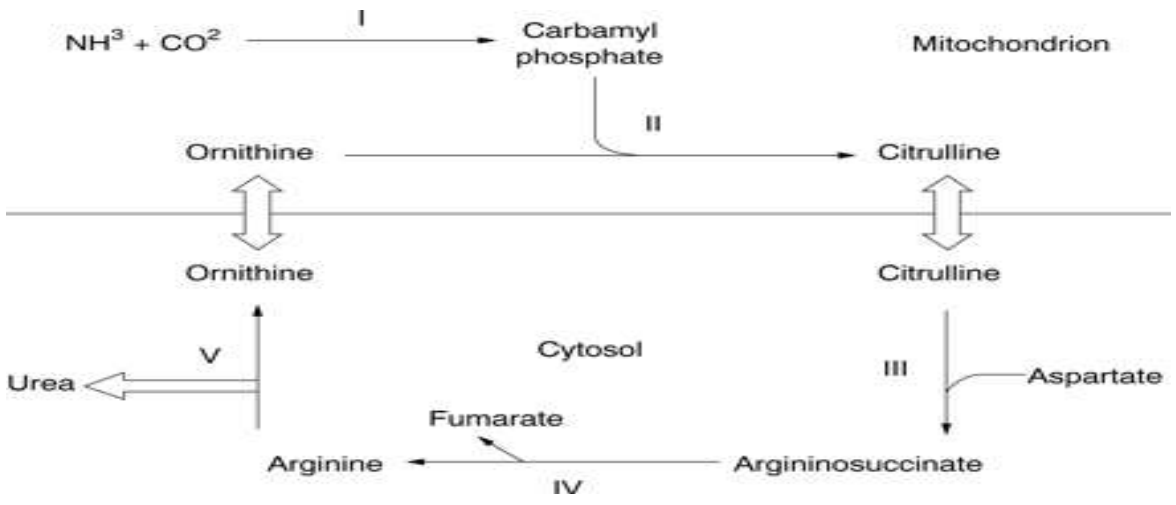

\section{Urea Cycle}

Hyperammonemia is a metabolic disturbance characterised by an excess of ammonia in the blood.Hyperammonemia is not a true disease; it is a sign that specific abnormalities that cause blood ammonia levels to become elevated may be present ${ }^{[6]}$. An elevated blood ammonia level, although it may be secondary, must never be ignored. Moreover, since the normal ureagenic capacity of the liver is so great in relation to physiologic load, such a finding points directly to an impairment of the urea cycle in the liver. 
Hyperammonemia can be congenital or acquired. Usually, congenital hyperammonemia is due to genetic defects in urea cycle and acquired hyperammonemia is due to liver dysfunction. Hyper ammonemia occurs when the ammonia production in the body is high exceeding the capacity of liver to metabolise ammonia or the ability of liver is compromised so that the liver can no longer metabolise ammonia to form urea. Hyper ammonemia by itself can cause both acute and chronic damage to brain cells.

The causes of hyperammonemia can therefore be divided into processes that increase ammonia production or decrease ammonia elimination. Many mechanisms plays role in increased ammonia production. The metabolism of proteins increases blood ammonia levels and can be seen with total parenteral nutrition, GI hemorrhage, steroid use ${ }^{[7-10]}$. Insulin has a global effect on protein metabolism, increasing the rate of protein synthesis and decreasing the rate of protein degradation. Thus, insulin deficiency or insulin resistance will lead to increased catabolism of protein. The increased rate of proteolysis leads to elevated concentrations in plasma amino acids. These amino acids serve as precursors for hepatic and renal gluconeogensis. In liver, the increased gluconeogenesis further contributes to the hyperglycemia seen in diabetic patients.

Insulin deprivation in type 1 diabetic patients causes a profound increase in catabolism, especially in skeletal muscle ${ }^{[11-14]}$. Moreover, this net muscle protein catabolism is due to a net increase in protein breakdown rather than a decline in protein synthesis. In contrast, despite substantial alterations in glucose and lipid metabolism, the effect of type 2 diabetes on changes in protein metabolism is at best subtle, and results are inconsistent ${ }^{[15]}$. So there are many studies in literature that are quite contradictory that some say protein synthesis alteration is only more in uncontrolled type 2 diabetes mellitus and some say that protein degradation also is more in them. One thing for sure is uncontrolled type 2 diabetes mellitus affects protein metabolism in one way or other and this might as well explain the reason behind hyperammonemia indicating high protein catabolism in uncontrolled type 2 diabetes mellitus. In the general population, insulin resistance has been associated with accelerated protein catabolism ${ }^{[16]}$.

Diabetes is associated with the occurrence of well described microvascular complications that affect different organs, leading most commonly to retinopathy, nephropathy and peripheral neuropathy, the development of which is dependent on the duration of the disease and glycaemia control ${ }^{[17]}$. the term "diabetic encephalopathy" was introduced in 1950 to describe the complication of diabetes resulting on brain dysfunction and leading to cognitive impairment. Along with these deficits on brain function, diabetes was also reported to induce structural alterations, neuronal loss, demyelination and gliosis ${ }^{18}$. The brain must expend energy to detoxify and to export the ammonia it produces. This is accomplished in the process of producing adenosine diphosphate (ADP) from ATP by the enzyme glutamine synthetase, which is responsible for mediating the formation of glutamine from an amino group. Diabetes mellitus is known to have disordered energy homeostasis that might also well explain the reason behind hyperammonemia in uncontrolled type 2 diabetes mellitus. Synthesis of glutamine also reduces the total free ammonia level circulating in the blood; therefore, a significant increase in blood glutamine concentration can signal hyperammonemia.

Infectious diseases are more prevalent in individuals with DM. The main pathogenic mechanisms are: hyperglycemic environment increasing the virulence of some pathogens; lower production of interleukins in response to infection; reduced chemotaxis and phagocytic activity, immobilization of polymorphonuclear leukocytes; glycosuria, gastrointestinal and urinary dysmotility.The conditions that can also increase ammonia production such as infection with urease splitting organisms ${ }^{[19],[20]}$. Urinary tract infections (UTIs) are more prevalent in individuals with DM and may evolve to complications and/or serious manifestations ${ }^{[21]}$.Others have suggested that increased production of ammonia present in type 2 diabetic patients occurs from tissue breakdown and mucositis.

Abnormal hormonal homeostasis for example hyperinsulinism has been associated with hyperammonemia in some patients.

Liver dysfunction especially decompensated liver disease, cirrhotic liver is the main cause for decreased ammonia elimination as the liver loses its function to metabolise ammonia. Certain infections are also prone to cause fulminant hepatic failure including hepatitis, varicella, Epstein barr virus, cytomegalo virus infections.HBV infection outbreaks have been reported among diabetic patients who share a blood glucose meter without cleaning and disinfecting between uses, associated with limited awareness of the high risk for HBV transmission during fingerstick blood glucose monitoring ${ }^{[22]}$. Several studies, from different countries, have reported that $13-33 \%$ of patients with HCV infection have diabetes, mostly type 2 diabetes mellitus (T2DM), compared with the prevalence of $4-10 \%$ for non-HCV control population ${ }^{[23]}$. T2DM is considered an extrahepatic manifestation of this infection.

Hyperammonaemia was thought to be due to slow transit constipation allowing increased absorption of ammonia into the mesenteric blood supply, sufficient to overwhelm hepatic excretory pathways.In the majority of patients, with normal liver function, excess ammonia is excreted by hepatic metabolism-via the urea cycle. However, hyperammonaemia sufficient to result in encephalopathy may still occur even in the setting of a patient with normal liver function. 
Increased intracellular fat content in skeletal muscle and liver associated with insulin resistance has led to the hypothesis that a mitochondrial defect in substrate oxidation exists in disorders of insulin resistance. In vivo measurements of metabolic fluxes through the tricarboxylic acid and oxidative phosphorylation with magnetic resonance spectroscopy have demonstrated multiple defects in mitochondrial function in skeletal muscle. A decrease in mitochondrial density and mitochondrial copy number has been reported in insulinresistant individuals ${ }^{[24]}$. Qualitative, quantitative, and functional perturbations in mitochondria have been identified and affect the cause and complications of diabetes. Moreover, as a consequence of fuel oxidation, mitochondria generate considerable reactive oxygen species (ROS) ${ }^{[25]}$.A portion of the cycle is mitochondrial in nature; mitochondrial dysfunction, whether genetically or pharmacologically induced, may impair urea production and result in hyperammonemia.

Non hepatic causes of hyperammonemia tend to present to a wide range of medical specialities with variable and episodic symptoms. Delay can result in the development of potentially life threatening complications such as encephalopathy.Early recognition is vital. Early assessment of blood ammonia levels help establish the diagnosis. In addition, they may lack accompanying clinical signs. Unless there is a high index of suspicion the diagnosis may easily be missed and the potential for reversibility and cure lost.

\section{Conclusion}

Type 2 Diabetes mellitus, a common disorder threatening the world to become a pandemic one shares a major influence on morbidity and mortality on patients which is directly linked with high plasma glucose levels. Hyperammonemia, a metabolic disturbance which is very common among chronic liver disease patients is now being recognized in many non hepatic causes. The study was done to find any association between the control of blood sugar levels and serum ammonia levels as it could well add upto the morbidity and even mortality. The findings of our study showed that serum ammonia levels are significantly higher among patients with uncontrolled type 2 diabetes mellitus than among healthy individuals. Causes for this could well include multiple factors like mitochondrial dysfunction, high protein catabolism, slow transit of bowel contents, subclinical and clinical infections, insulin resistance, all of which revolve around common basic etiology of uncontrolled plasma glucose levels, which tends to happen in uncontrolled type 2 diabetes mellitus patients. Hence it is worth while to do serum ammonia levels in uncontrolled type 2 diabetes mellitus patients, especially as a screening and so its early diagnosis and preventive measures could avert serious consequences on brain.

\section{Conflictof interest :}

The authors declare no conflict of interest.

\section{References}

[1]. Joshi SR, Parikh RM. India - diabetes capital of the world: now heading towards hypertension. J Assoc Physicians

[2]. India. 2007;55:323-4. [PubMed][2]. Kumar A, Goel MK, Jain RB, Khanna P, Chaudhary V. India towards diabetes control: Key issues. Australas Med

[3]. J. 2013;6(10):524-31.[3].Wild S, Roglic G, Green A, Sicree R, King H. Global prevalence of diabetes-estimates for the year 2000 and projections for

[4]. 2030. DiabetesCare. 2004;27(3):1047-53. Whiting Dr, Guariguata L, Weil C, Shawj. IDF Diabetes atlas: Global estimates of the prevalence of diabetes for 2011 and 2030. Diabetes Res ClinPract. 2011;94:311-21.

[5]. Non-hepatic hyperammonaemia: an important, potentially reversible cause of encephalopathy, hawkes et al, Postgrad Med J 2001;77:717-722.

[6]. Bosoi CR, Rose CF. Identifying the direct effects of ammonia on the brain. Metab Brain Dis. 2009 Mar. 24(1):95-102

[7]. Summar M, Barr F, Dawling S, et al. Unmasked adult-onset urea cycle disorders in the critical care setting. Crit Care Clin 2005; (suppl):S1-S8

[8]. Felig DM, Brusilow SW, Boyer JL. Hyperammonemic coma due to parenteral nutrition in a woman with heterozygous ornithine transcarbamylase deficiency. Gastroenterology 1995; 109:282-284

[9]. Benque A, Bommelaer G, Rosental G. Chronic vomiting in a case of citrullinaemia detected after treatment by total parenteral nutrition. Gut 1984; 25:531-533

[10]. Trivedi M, Zafar S, Spalding MJ, et al. Ornithine transcarbamylase deficiency unmasked because of gastrointestinal bleeding. J ClinGastroenterol 2001; 32:340-343

[11]. Nair KS, Garrow JS, Ford C, Mahler RF, Halliday D: Effect of poor diabetic control and obesity on whole body protein metabolism in man. Diabetologia $25: 400-403,1983$.

[12]. Umpleby AM, Boroujerdi MA, Brown PM, Carson ER, Sonksen PH: The effect of metabolic control on leucine metabolism in

[13]. type 1 (insulin-dependent) diabetic patients. Diabetologia $29: 131-141,1986$

[14]. Tessari P, Nosadini R, Trevisan R, De Kreutzemberg SV, Inchiostro S, Duner E, Biolo G, Marescotti MC, Tiengo A, Crepaldi G: Defective suppression by insulin of leucine-carbon appearance and oxidationin type 1 , insulin-dependent diabetes mellitus. $J$ ClinInvest $77: 1797-1804,1986$

[15]. Nair KS, Ford GC, Ekberg K, Fernqvist-Forbes E, Wahren J: Protein dynamics in whole body and in splachnic and leg tissues in [16]. type I diabetic patients. J ClinInvest $95: 2926-2937,1995$

[17]. Halvatsiotis P, Short KR, Bigelow ML, Nair KS: Synthesis rate of muscle proteins, muscle functions, and amino acid kinetics in [18]. type 2 diabetes. Diabetes $\mathbf{5 1}: 2395-2404,2002$.

[19]. Ronco C, Cruz DN (eds): Hemodialysis - From Basic Research to Clinical Trials. ContribNephrol. Basel, Karger, 2008, vol161, pp 138-144. 


\section{Hyperammonemia in uncontrolled Type 2 Diabetes Mellitus}

[20]. Type 2 diabetes mellitus and its complications: from the molecular biology to the clinical practice. Malecki MT Rev Diabet Stud. 2004 Spring; $1(1): 5-8$

[21]. CNS manifestations of diabetes mellitus.DeJong RN Postgrad Med. 1977 Jan; 61(1):101-7.

[22]. Kaveggia FF, Thompson JS, Schafer EC, et al. Hyperammonemic encephalopathy in urinary diversion with urea-splitting urinary tract infection. Arch Intern Med 1990; 150:2389-2392.

[23]. Samtoy B, DeBeukelaer MM. Ammonia encephalopathy secondary to urinary tract infection with Proteus mirabilis. Pediatrics1980; 65:294-297

[24]. Urinary tract infections in patients with diabetes mellitus: epidemiology, pathogenesis and treatment. Geerlings SE Int J Antimicrob Agents. 2008 Feb; 31 Suppl 1():S54-7.

[25]. Eliminating the blood: ongoing outbreaks of hepatitis B virus infection and the need for innovative glucose monitoring technologies. Thompson ND, Perz JF J Diabetes Sci Technol. 2009 Mar 1; 3(2):283-8.

[26]. Hepatitis C virus and type 2 diabetes.Negro F, Alaei M World J Gastroenterol. 2009 Apr7; 15(13):1537-47.

[27]. Ghani et al, mitochondrial dysfunction, insulin resistance and type 2 diabetes mellitus, currdiab rep, 2008 Jun;8(3):173-8.

[28]. Sivitz et al, mitochondrial dysfunction from molecular mechanisms to functional significance and therapeutic opportunities, anti oxid redox signal, $2010 \mathrm{Apr} ; 12(4): 537-77$. 